\title{
FRUSTRACIÓN DOCENTE Y DESAFÍOS QUE LAS PRÁCTICAS INFORMACIONALES TRAEN AL ESCENARIO EDUCATIVO TEACHERS DISCOMFORT AND CHALLENGES THAT THE INFORMATIONAL PRACTICES BRING TO THE EDUCATIONAL SCENARIO
}

\author{
Volumen 14, Número 3 \\ Setiembre - Diciembre
}

pp. 1-18

Este número se publicó el 30 de setiembre de 2014

José Manuel Corona Rodríguez

Revista indizada en $\underline{\text { REDALYC}}$, SCIELO

Revista distribuida en las bases de datos:

CATÁLOGO DE LATINDEX, IRESIE, CLASE, DIALNET, DOAJ, E-REVIST@S, SHERPA/ROMEO, QUALIS, MIAR

Revista registrada en los directorios:

ULRICH'S, REDIE, RINACE, OEI, MAESTROTECA, PREAL, $\underline{\text { CLACSO }}$ 


\title{
FRUSTRACIÓN DOCENTE Y DESAFÍOS QUE LAS PRÁCTICAS INFORMACIONALES TRAEN AL ESCENARIO EDUCATIVO TEACHERS DISCOMFORT AND CHALLENGES THAT THE INFORMATIONAL PRACTICES BRING TO THE EDUCATIONAL SCENARIO
}

\author{
José Manuel Corona Rodríguez ${ }^{1}$
}

Resumen: Este ensayo reflexiona algunas directrices que están cambiando el escenario educativo en la actualidad. Repasa la frustración y la incapacidad con la que miembros de las instituciones educativas afrontan los desafíos que las prácticas informacionales traen a los nuevos escenarios del aprendizaje. Se describe un caso (que ha cobrado visibilidad a lo largo de varios años), en el que un profesor decide hacer pública su frustración y consecuente renuncia ante la incapacidad para establecer empatía con sus estudiantes. Se reflexionan los imaginarios sobre el poder de la tecnología en la educación. A modo de conclusión se plantean elementos y enfoques que cada vez más se advierten indispensables de investigar en el escenario educomunicativo.

Palabras clave: APRENDIZAJE NO FORMAL, INSTITUCIONES EDUCATIVAS, PRÁCTICAS INFORMACIONALES, FRUSTRACIÓN PROFESOR, DOCENTE.

Abstract: This essay thinks over some guidelines that are changing the education scenario today. Review the frustration and inability with which members of educational institutions face the challenges that the informational practices bring to the new learning scenarios. One case (that has gained visibility over several years), in which a teacher decides to make public his frustration and consequent resignation given the inability to empathize with their students is described. It also thinks over the imaginaries about the power of technology in education. As a way of conclusion it raises elements and approaches that are increasingly essential to investigate in the educommunicative scenario.

Key words: NON-FORMAL LEARNING, EDUCATIONAL INSTITUTIONS, INFORMATIONAL PRACTICES, FRUSTRATION, PROFESOR, TEACHER.

\footnotetext{
1 Profesor de Periodismo y Comunicación de la Universidad de Guadalajara, México. Doctorando en Educación por la misma casa de estudios.
}

Dirección electrónica: corona.jm.r@gmail.com

Ensayo recibido: 17 de enero, 2014

Devuelto para corrección: 30 de junio, 2014

Aprobado: 31 de julio, 2014 


\section{El escenario educativo actual: la comunicación en el centro}

Hablar de la importancia que tienen las tecnologías de la información y la comunicación (TIC) en la vida cotidiana, es un lugar común; solamente se necesita mirar con cierto detenimiento a nuestro alrededor, para advertir que las tecnologías (no solo las informacionales y de comunicación) rigen y condicionan las prácticas y actividades humanas en muchos niveles. A pesar de esta recurrencia actual, existe una marcada tendencia para encontrar aún posturas antagónicas sobre los cambios que van aconteciendo en las sociedades, y sin importar que el lector sea tecnofóbico o tecnofílico (o ninguna de las anteriores), es irrefutable que el desarrollo técnico ha acompañado a la humanidad desde hace mucho tiempo (Basalla, 1991).

Como punto de partida, se reconoce que existe un tipo de tecnologías que son especialmente educativas, sin embargo, aquí se apuesta por aceptar que las tecnologías (todas), tienen un potencial educativo y de aprendizaje. En este sentido, tanto una pizarra, como un lápiz, como un proyector, como una conexión a Internet, o un libro, son tecnologías que potencian el aprendizaje; en todos esos casos hay historia evolutiva que antecede su significación. La clave es entender que las tecnologías poseen disposiciones que les permiten tener mayor o menor potencialidad educativa y de aprendizaje, pero que son los sujetos, los actores sociales, los que actualizan esas posibilidades a partir de interacciones y actividades específicas.

Martín-Barbero sugería, al finalizar el siglo pasado (1997, p. 18), que un elemento definitorio de las relaciones sociales es el tránsito de una sociedad donde el conocimiento legítimo estaba asociado a un "sistema educativo" con instituciones, grados y reglas, medios y lenguajes muy específicos para realizar la educación, a una situación donde esta se puede efectuar en cualquier lugar, en cualquier momento, a través de varios lenguajes y medios, bajo condiciones muy diferentes a aquellas que mediaron lo que hoy se puede llamar "el modo escolar de educar", el "modo institucional de construir conocimiento" y el "modo letrado de aprender". Educar y aprender ya no es dominio (como no la ha sido desde hace mucho tiempo) exclusivo de las instituciones académicas formales. Reflexionar los procesos educativos implica reconocer como punto inicial que hay educación y aprendizaje más allá de las aulas y las escuelas (Bauman, 2005).

La educación se ha descentrado, y ya no se circunscribe a lugares y momentos delimitados, sino que ocurre, en palabras de Guillermo Orozco (2004, p. 121), "un desbordamiento de los lugares y los momentos que ha llevado al proceso de enseñanza- 
aprendizaje a otros contextos". Es importante resaltar que durante mucho tiempo (producto de la herencia positivista), las tecnologías / pantallas se han visto como una fuente poco válida o limitada por su especial énfasis en desarrollar contenido para el entretenimiento.

Desde esta lógica se pone en duda la importancia que la institución educativa ha puesto en el proceso de enseñanza - aprendizaje, pues se ha centrado en atender la enseñanza, desarrollando las políticas educativas que supongan una mejora, lo cual no implica que con estas también mejore o siquiera se atiendan el aprendizaje. En este sentido, Orozco (2004, p. 121) afirma que "esto históricamente ha mostrado ser una falacia que no se puede seguir sosteniendo. Es equiparable a esa otra falacia del pensamiento económico que postula que fortaleciendo el capital y a los capitalistas, naturalmente se generará riqueza para todos en una sociedad". El aprendizaje trasciende a la enseñanza, puesto que la primera no depende exclusivamente de quien planea y evalúa su cumplimiento y funcionamiento, sino de los actores involucrados, dejando espacios para la improvisación y las lógicas hipertextuales e innovadoras propias de las nuevas tecnologías (Ferrés, 2011).

Para Roberto Aparici (2005), la incorporación de una tecnología a un ambiente educativo no significa que esté asociada a una nueva concepción de enseñanza, sino todo lo contrario, por desgracia, es fácil intuir que muchas veces las nuevas tecnologías se incluyen para reproducir una vieja práctica pedagógica. La gran mayoría de los esfuerzos en la incorporación de la tecnología a los espacios, ámbitos y prácticas educativas, están pensados y son ejecutados desde las visiones más burocráticas posibles (Crovi Druetta, 2002).

Los modelos mecanicistas de comprender la relación entre la tecnología y los procesos educativos predominan; en muchos de ellos, el profesor sigue tratando a los alumnos como recipientes de la información y no como agentes de colaboración, sin tener en cuenta el intercambio y la co-creación, que son las prácticas predominantes en Internet (Cobo y Moravec, 2011). En bastantes casos continúa la lógica de la distribución, propia de los medios de comunicación de masas, y no se desarrollan las potencialidades de las tecnologías informacionales y de las experiencias que se están generando en esos entornos (Aparici y Silva, 2012).

Muchas políticas educativas han priorizado la inclusión tecnológica en los centros educativos, pero de poco sirve actualizar las escuelas con nuevos dispositivos técnicos, si 
se usan basados en un paradigma de transmisión (Liñares, Rivero, Velleggia, y Zermeño, 2009). Se necesita hacer énfasis en que no solo se trata del aprendizaje que es resultado de las prácticas educativas formales o informales, sino además de que las generaciones digitales están atendiendo cambios notables en la transmisión cultural, basada en una cultura de la interacción, lo cual resulta muy contradictorio con los modelos tradicionales en que se entienden y efectúan los procesos educativos (Feixa, 2010).

Para Castells (2009), existe una brecha cada vez más grande entre la realidad extraescolar dinámica, hiperinformada, fragmentada y transmediática, y los tiempos pausados, unidireccionales, monomediales y jerárquicos de la institución escolar. Roberto Aparici (2011) sugiere que se trata más bien de reconocer que las tecnologías digitales y las redes sociales han hecho visibles las prácticas comunicativas que imperan en los modelos educativos formales, transmisivas y reproductoras, en donde la institución actúa como si tratara de un medio de comunicación masivo, en el que están claramente definidos el emisor y el receptor. $Y$ cuando se logra incorporar los dispositivos tecnológicos informacionales, es para repetir las viejas concepciones de enseñanza tradicional.

Existen otras voces que sugieren que la educación debe insertarse en las lógicas productivas comunicacionales de los medios que privilegian lo interactivo, destacando la importancia de lo emocional y lo sensitivo, para lograr estar al ritmo y hacer concordancia con los estudiantes (Ferrés, 2008). La cultura del espectáculo ha condicionado la forma en que se experimenta estar en el mundo, dando mucho más importancia a la dimensión de las emociones que a la de las ideas, como todavía se espera que sea a partir de modelo de transmisión educativo (Ferrés, 2000).

Las tecnologías del ánimo, como las nombra James Lull (2008), serían los dispositivos que centran su proceso comunicativo en la posibilidad interactiva, pues es esta, la que define en gran medida la era de la comunicación en la que se vive. Las interacciones comunicativas suponen que los ciudadanos sean más activos, puesto que se tiene acceso a mayor cantidad de canales, códigos y referentes culturales (no se cree que esto sea mejor o peor, sino que se entiende como una posibilidad que tales interacciones comunicativas alientan). 


\section{La frustración y las mutaciones en el aprendizaje}

Uno de los principales síntomas que indican que algo ya no funciona en las prácticas educativas tradicionales, es el constante aburrimiento que sufren los estudiantes de todos los grados en las aulas escolares. El aburrimiento como variable de comportamiento sugiere que el sujeto que lo padece no está en sintonía con aquello que lo produce. La naturaleza interactiva y multimediática de los nuevos medios de comunicación impone un reto mayúsculo a las escuelas, puesto que al intentar competir con los constantes e intensos impulsos informacionales a los que están habituados los estudiantes, no tienen oportunidad de generar una experiencia significativa (Corea, 2004).

Asumir que el aburrimiento crónico de los estudiantes es un indicio de que los procesos educativos formales no funcionan como se espera, es apenas la punta del iceberg del problema. Hablar de aburrimiento implica también reflexionar la naturaleza de la atención, y la importancia que tiene esta en los procesos de enseñanza-aprendizaje. La atención es una de las disposiciones actitudinales más importantes en la lógica en que opera la educación formal en su visión tradicional, puesto que supone que el estudiante tendrá disposición y le dedicará cierto esfuerzo a la actividad reina de la educación tradicional, la lectura (Dussel, 2009).

La actividad de lectoescritura adquiere una dimensión superior al incluir en los procesos de significación los medios de comunicación y sus contenidos. La idea de que la textualidad (y el libro por extensión) es el centro de la educación, perdió importancia desde hace muchas décadas, a la luz de los descubrimientos sobre la lectura de imágenes y materiales audiovisuales y la complejidad que implica descifrarlos. Significar imágenes y contenidos audiovisuales nunca ha sido una actividad sencilla y sin valor educativo, muy a pesar de los viejos modelos teóricos de la comunicación de masas (Pedró, 2011).

Lo que es evidente es que existe un desajuste entre las maneras en que se acercan los estudiantes a la lectoescritura en sus múltiples posibilidades, y lo que la textualidad tradicional (lineal, previsible, secuencial) tiene que ofrecer en comparación con la textualidad multilineal, reticular, rizomática, virtual y multimediática.

Pero el aburrimiento no es exclusivo de los estudiantes, también los profesores están sufriendo las vicisitudes de intentar generar prácticas y contenidos que posibiliten algún grado de atención. El aburrimiento y la desconexión entre profesores y alumnos es un síntoma contundente de que la experiencia educativa tradicional enfrenta una crisis. La 
carente empatía entre profesores y alumnos es signo irrefutable, cada vez más, de que los sistemas educativos no están resolviendo uno de los principales objetivos de la educación: generar procesos de comunicación significativos entre los participantes.

Un caso icónico por su visibilidad mediática es el descrito a continuación. Se reproducen algunos fragmentos de la carta titulada; “¿Por qué dejo mi cátedra en la universidad?", en la que el profesor Camilo Jiménez (2011, párrs. 1-2), explica las motivaciones que tuvo para abandonar la docencia en la Universidad Javeriana de Bogotá. ${ }^{2}$

"Un párrafo sin errores. No se trataba de resolver un acertijo, de componer una pieza literaria o de encontrar razones para defender un argumento resbaloso. No. Se trataba de escribir un párrafo que condensara un texto de mayor extensión. Es decir, un resumen. Un resumen de un párrafo. Donde cada frase dijera algo significativo sobre el texto original. Donde se atendieran los más básicos mandatos del lenguaje escrito -ortografía, sintaxis- y se cuidaran las mínimas normas de cortesía que quien escribe debe tener con su lector: claridad, economía, pertinencia..."

“...Veinticinco muchachos no pudieron escribir el resumen de una obra en un párrafo atildado, entregarlo en el plazo pactado y usar un número de palabras limitado, que varió de un ejercicio a otro. Estudiantes de comunicación social entre su tercer y su octavo semestre, que estudiaron doce años en colegios privados..."

“...No me he sintonizado con los tiempos que corren. Mis clases no tienen presentaciones de Power Point ni películas, a lo más vemos una o dos en todo el semestre. Quizá ya no es una manera válida saber qué es una crónica leyendo crónicas, y debo más bien proyectarles diapositivas con frases en mayúsculas que indiquen qué es una crónica y en cuántas partes se divide. Mostrarles la película Capote en lugar de leer $A$ sangre fría. No debí insistir tanto en la brevedad, en la economía, en la puntualidad..."

Se puede identificar en estas afirmaciones, la validez que se le otorga al texto impreso como vehículo para acceder al conocimiento, además de una perspectiva vinculante entre la educación y la tecnología, en la que se deja ver un imaginario sobre

2 Este caso detonó un amplio debate en redes sociales a finales de 2011. Aquí se puede leer la respuesta de uno de sus estudiantes y muchos comentarios al respecto. http://alfinvictoria.blogspot.mx/2011/12/cartapara-camilo-jimenez.html?spref=fb 
esta, donde figura la importancia de incorporarla a la educación formal, a pesar de reproducir modelos tradicionales.

“...Estoy por pensar que la curiosidad se esfumó de estos alumnos míos desde el momento en que todo lo comenzó a contestar ya, ahora mismo, el doctor Google."

Es posible identificar un discurso antagónico entre apocalípticos e integrados sobre las maravillas o los perjuicios (según sea el caso) de la tecnología y lo que esta le hace a los estudiantes. El profesor Jiménez sigue con su argumentación cargada de sarcasmo e ironía:

“...Dejo la cátedra porque no me pude comunicar con los nativos digitales. No entiendo sus nuevos intereses... Quizá la lectura sea ya otra cosa con la que no me pude sintonizar. De pronto ya no se trata de comprender un texto, de dialogar con él. Quizá la lectura sea ahora salir al mar de Internet a pescar fragmentos, citas y vínculos."

Es evidente en el argumento del profesor Jiménez, cierto desagrado a la dinámica con la que sus estudiantes han ejecutado las tareas asignadas. Sin embargo, no deja de ser una situación apremiante que un profesor tenga tal grado de frustración sobre la incapacidad para entrar en sintonía con los estudiantes. Al final de cuenta "...el educador es un comunicador, y nadie puede comunicar de manera eficaz si no está en sintonía con los receptores, sino es capaz de conectar con ellos" (Ferrés, 2000, p. 43).

Es posible encontrar posturas similares frecuentemente, como la de Nicholas Carr (2011), quien en uno de sus libros pregunta: Superficiales ¿Qué está haciendo Internet con nuestras mentes?, o la visión multicitada de Sartori, al sugerir que se vive en un estado de indefensión en donde lo visual suplanta los preceptos racionales de conocer y apropiarse del mundo (Scolari, 2011).

Pero los argumentos que desde la educación institucionalizada se pueden formular, pocas veces escuchan las voces de los educandos. Uno de los estudiantes del profesor Jiménez le responde:

“...considero una falencia de su parte creer que el único conocimiento válido es el que reside en los libros. Porque señor Jiménez, esa es la premisa que está detrás de toda su exposición. Entiendo que esa pueda ser su visión como editor (y en último término, como profesor), y que cuando usted tenía la edad de sus estudiantes 
esa fuera la única, pero déjeme contarle que hay otras formas, y son igualmente válidas...".

En este argumento es visible uno los puntos medulares en el cambio y dilema que las instituciones educativas enfrentan. El acceso a la información ha supuesto un peligro para la legitimación del conocimiento en su modalidad tradicional. El conocimiento y la información han salido de las aulas para instalarse en otros ámbitos, más interesantes y dinámicos para las nuevas generaciones (Scolari, 2009). Esta circunstancia (sumada a las disposiciones técnicas de las TIC, como el hipertexto y la interactividad) deviene en un cambio, o por lo menos en cuestionar conceptos como el de la lectura y la alfabetización.

“... hice un conteo similar al que usted hizo con sus estudiantes. He cursado un total de 29 materias, y nunca he repetido profesor. De esos 29 profesores, 3 me han enseñado algo, lo que sea, y uno ha hecho el esfuerzo. 25 profesores han pasado por mi vida desapercibidamente. ¿25 estudiantes no le dieron la talla? Bueno, a mí, 25 profesores no me han dado la talla..."

Que un estudiante sea capaz de enunciar con toda claridad que en su historial académico ha existido un alto porcentaje de profesores irrelevantes, hace evidente, la cantidad de desvinculación por parte de los estudiantes para con sus profesores, y en general para con el sistema educativo. Continúa y cierra la exposición del estudiante en respuesta al profesor en cuestión.

"Nadie está obligado a permanecer en un lugar donde no quiere estar. Lo que me parece injusto, es que la culpa (porque sí, señor Jiménez, hay culpables en su texto y es claro) sea de sus estudiantes, que "no pudieron" con usted...."

"La verdad, agradezco la sensatez que reside en el hecho de haberse ido. Me imagino que a usted no le gustan los médicos que, durante la consulta, no lo miran a los ojos. A mí no me gustan los profesores que no pueden asumir la responsabilidad de enseñar. Al igual que usted, termino esta carta con un incómodo nudo en la garganta."

Se advierte claramente el desagrado y molestia por la manera en que se ha decidido afrontar el caso, además de que se nota la importancia que tiene establecer 
vínculos afectivos y de empatía que posibiliten tener disposición al aprendizaje y limiten el aburrimiento.

La educación es un proceso premeditado y planeado, que tiene como objetivo central, compartir información, significados, conocimientos y habilidades que de algún modo son necesarios para los miembros de un grupo social. En este sentido, la comunicación es esencial (por su naturaleza intrínseca) para alcanzar dichos objetivos (Ferrés, 2011). Así pues, queda de manifiesto que existen interacciones comunicativas que dificultan las relaciones entre profesores y alumnos, exacerbando frustraciones y evidenciando fracasos educativos.

En la argumentación del profesor Jiménez y en la del estudiante que le responde, es evidente que uno de los aspectos fundamentales en el proceso comunicativo respecto de la educación y el aprendizaje, es la textualidad. Jesús Martín-Barbero (1997) sugiere que con las nuevas tecnologías, no solo se accedemos a tecnicidades que posibilitan interacciones comunicativas particulares, sino que además, se está ante un tipo de textualidad que obstaculiza el acceso a la información escrita, puesto que esta se fragmenta y expande en todo momento. "La gramática de construcción de los nuevos relatos se alimenta del zapping y desemboca en el hipertexto, lo que implica un doble y muy distinto movimiento que la reflexión crítica tiende confundir anulando las contradicciones que los ligan". (Martín-Barbero, 1997, p. 14)

\section{Imaginarios sobre el poder de la tecnología}

La relación entre la escuela y las nuevas tecnologías informacionales es uno de los temas más en boga en la agenda educativa contemporánea. La aparente separación entre la educación y las tecnologías ha hecho que se tomen muchas acciones (casi siempre centradas en la escuela y en la enseñanza) que intentan actualizar e incorporar dispositivos comunicacionales a las escuelas. Estos esfuerzos casi siempre son resultado de políticas educativas concebidas en los ámbitos más burocráticos posibles (Crovi, 2002).

El imaginario tecnológico está constituido desde múltiples dimensiones, en las que lo educativo tiene un peso importante, en primer término porque supone un cambio radical en la manera en que se accede a la información y cómo esta condiciona la experiencia y procesos de cognición. Y segundo, porque se intuye que la tecnología debe ser insertada 
a los espacios educativos para llenar los vacíos que las dinámicas comunicativas generan entre estudiantes e instituciones (Ferrés, 2008).

Retomando una visión en que se asume a la tecnología inmersa en procesos de convergencia, remediación y mutaciones, es peligroso dar por hecho que lo técnico en sí mismo puede transformar prácticas situadas en contextos institucionales muy difíciles de modificar. Inés Dussel (2009, p. 14) afirma que "la irrupción de nuevas tecnologías vino acompañada, muchas veces, de la diseminación de discursos optimistas y utópicos sobre su poder transformador y redentor de la exclusión o la ignorancia de la población", lo que hace que se siga privilegiando la visión del aprendizaje formal solamente adicionado con tecnología educativa.

Muchos de estos discursos optimistas y redentores, no especifican cómo se deben usar las tecnologías en los espacios educativos. La mayoría se limita a engrandecer las virtudes y posibilidades que los dispositivos técnicos poseen, sin puntualizar en la alfabetización digital necesaria para su ejecución. Es preciso decir, en este contexto, que mucho del imaginario que se construye respecto de las TIC y la educación, es generado desde las dinámicas comerciales para perseguir una finalidad económica, circunstancia que propicia una visión determinista de la tecnología y de sus efectos en la sociedad y en la educación (Dussel, 2013).

En el terreno de lo académico existe una tendencia muy marcada de desarrollar investigaciones que buscan la incorporación y vinculación de las tecnologías en el aula, de una manera mecanicista (Cano, 2012). Pareciera que la perspectiva más evidente es la de incorporar las nuevas tecnologías de la información y la comunicación a los espacios educativos formales, e institucionalizarlas, siendo que los procesos de apropiación tecnológica de los estudiantes pueden rebasar por mucho, los intentos de incorporación.

Investigar la relación entre educación y comunicación implica hablar de tecnologías de la información y la comunicación, pero tal vínculo no es exclusivo de los nuevos medios, pues tiene una amplia tradición y desarrollo en el estudio de los medios de comunicación de masas, lo cual implica que de esa tradición proviene una buena cantidad de conceptos, enfoques y teorías muy valiosos, para pensar lo que se ha dado por llamar el ecosistema hipermedial contemporáneo (Scolari, 2008, p. 34).

Se necesita hacer énfasis en que no solo se trata del aprendizaje que deviene de las prácticas educativas formales, no formales o informales, sino además que las generaciones más jóvenes están atendiendo cambios notables en la transmisión cultural, 
basada en una cultura de la interacción, la cual resulta muy contradictoria con los modelos tradicionales en que se entienden y efectúan los procesos educativos (Feixa, 2010).

El ecosistema comunicacional contemporáneo alienta prácticas sociales particulares, como el trabajo colaborativo y la inteligencia colectiva. En este sentido, investigar las interacciones comunicativas en el marco de las narrativas transmediáticas, excede el alcance de las nuevas o viejas tecnologías, dado que se invita a reflexionar acerca de la domesticación y la incorporación de los dispositivos informacionales en los procesos educativos, más allá de su grado de institucionalización (Cobo y Moravec, 2011).

\section{Sobre la investigación pendiente}

Es imprescindible reconocer el rol de la institución educativa a lo largo de los años, y el valor que tiene especialmente en sociedades como las latinoamericanas, en donde se percibe un profundo clima de inequidad. La relación existente (y que se ha trabajado desde diferentes perspectivas, enfoques y contextos) entre educación y comunicación, resulta capital para investigar, por dos razones: la primera, por la irrefutable influencia que (durante décadas) han tenido los medios de comunicación de masas en los sujetos y las formas de aprender y aprehender el mundo, y la segunda, por el cambio tan evidente que la comunicación como proceso, ha sufrido con la irrupción de los dispositivos tecnológicos informacionales, lo que ha supuesto modificaciones sustanciales al panorama educativo en múltiples dimensiones.

Pero mientras en otros países como los Estados Unidos, Brasil, Argentina, Canadá y España (y una larga lista de la comunidad europea), se está trabajando temas por demás innovadores y acordes a la realidad social de lo que ocurre en los espacios de interacción comunicativa, con los dispositivos móviles y las tecnologías conectadas a Internet, en una buena parte de América Latina todavía se dedica esfuerzos a "insertar" o "adaptar" la tecnología a la escuela, sin lograr aceptar que hay (también) educación y sobre todo aprendizaje (que puede ser más significativo), fuera de los espacios institucionalizados (Johnson, Adams, Cummins, Estrada, Freeman y Ludgate, 2013).

Durante las últimas tres décadas del siglo pasado, se trató de insertar la tecnología del momento a las aulas y espacios educativos (Orozco, 2012). Son conocidos los esfuerzos realizados para colocar a la televisión (y la radio en algunos casos) como el centro de un tipo de educación (Scolari, 2009). La dimensión interactiva de las tecnologías 
comunicativas trasciende los intentos de adaptación, por muy buenos o efectivos que aparenten ser, siempre que no se logre comprender la lógica comunicativa (lo que implica pensar la naturaleza hipertextual, interactiva y transmedial de las mal llamadas nuevas tecnologías de la información y la comunicación, y las posibilidades evolutivas de las interfaces que permiten los escenarios de comunicación actual) detrás de cada tipo de medio y su mediación; pero tales intentos están condenados al rechazo de los estudiantes (Cobo y Moravec, 2011).

Un porcentaje considerable de la insatisfacción que causa la manera en que se plantean las investigaciones sobre educación y comunicación, obedece a que se reduce la comunicación a los medios (y la educación a la instrucción formal). Esta reducción es quizás herencia de la amplía influencia que las ideas (más populares) de Marshall McLuhan y la escuela de Toronto (Islas, 2011), aportaron al estudio de los medios. La obra de McLuhan es mucho más amplia y completa, lejos de la multicitada idea de que el medio es el mensaje, que se ha vuelto un lugar común para justificar enfoques simplistas sobre la manera de investigar los medios y sus efectos (Elizondo, 2009).

Una relación que parece necesaria de reflexionar y que de algún modo está implícita en la gran mayoría de las investigaciones sobre tecnologías de la comunicación y educación, es la de ocio-trabajo. Se puede observar una visión centrada en el trabajo como categoría implícita, desde la cual se asume que todo lo que ocurre en esa dimensión tiene una utilidad especial, a diferencia de lo que sucede en los espacios y tiempos de ocio que los sujetos tienen cotidianamente. Un buen porcentaje de las investigaciones en educación y tecnologías parten de la premisa de que la dimensión del trabajo, que también puede considerar lo institucional y lo formal, implica efectividad en el empleo de los dispositivos tecnológicos y de los contenidos disponibles, circunstancia muy discutible, puesto que implicaría una visión centrada en el trabajo como categoría implícita, desde la cual se asume que todo lo que ocurre en esa dimensión, tiene una utilidad auténtica, a diferencia de lo que sucede en los espacios y tiempos de ocio que los sujetos tienen cotidianamente.

\section{Conclusiones: Reflexionar la textualidad y las narrativas}

Existen apuestas como la de Carlos Scolari (2013), que propone el concepto de interfaz para reflexionar las textualidades y las formas de interacción que se desarrollan en las nuevas tecnologías de la información. Este periodo se caracterizaría por la 
posibilidad de los medios de expandir el texto de una forma automatizada, lo que facilita la construcción de una (hiper)textualidad multimedia y multilenguaje, y produce un tipo de textualidad audiovisual interactiva, que le otorga autonomía y posibilidad de gestión a los usuarios.

Se percibe la necesidad de revisar el paradigma dominante educativo, a la luz de la aparición de nuevos entornos comunicativos propiciados por las tecnologías informacionales. Para Joan Ferrés (2011, p. 2), "de los hallazgos de la neurociencia se desprende, que sólo se puede comprender el poder socializador de las pantallas tomando conciencia de la manera como se gestionan en ellas las emociones". Lo sensorial cada vez cobra más importancia en los escenarios comunicativos, especialmente porque las interacciones se desarrollan en un ambiente multimedia, en donde participan varios sentidos. La sensorialidad de la comunicación juega en favor de las tecnologías informacionales que apuestan más por la concreción que por la abstracción, imponiendo un reto muy complejo para el modelo educativo centrado en la transmisión.

El paradigma educativo se enfrenta a un cambio que trasciende las tecnicidades de los dispositivos informacionales. "Seducir (se-ducere) significa llevar a uno a otra parte, sacarle de sí y conducirle a otra dimensión. Solo se puede educar si se es capaz de seducir" (Ferrés, 2008, p. 2). La efectividad de un comunicador pasa en buena medida por la capacidad de llamar la atención, de sorprender, de despertar interés, y cuando un profesor tiene que competir con textualidades interactivas y dinámicas su discurso unidireccional y centrado en el libro, se ve en complicaciones serias.

Es preciso destacar que durante varias décadas se ha reflexionado la urgencia de desarrollar competencias comunicativas que puedan agilizar y hacer más eficiente el proceso educativo. "Con nuevas o viejas tecnologías es imprescindible preguntarse sobre nuevas formas de enseñar y aprender. Los cambios metodológicos, la búsqueda de nuevos modelos pedagógicos y las prácticas interactivas basadas en el diálogo son cuestiones que están más allá del uso de una tecnología" (Aparici, 2011, p. 9).

Guillermo Orozco (2011) nombra a este contexto cultural, como "la condición comunicacional contemporánea", que sería ese tránsito de ser audiencias caracterizadas por la recepción, a ser audiencias definidas por las actividades de creación, producción y emisión. La aportación toma como eje trascendental los cambios de estatus de las audiencias frente a las pantallas y las formas de ser a partir de ellas. Se puede pensar 
entonces que se magnifica una "cultura de la participación" en la que incluso se alcanzan procesos complejos, como el de la "autocomunicación de masas" (Castells, 2009).

Durante muchos años los productos de la cultura de masas han tenido una construcción negativa respecto de la alta cultura y la institución educativa formal, pero como sugiere Johnson (citado en Scolari, 2013, p. 70) “...la cultura de masas del siglo XXI, está generando obras de alta complejidad que exigen un esfuerzo cognitivo adicional para ser interpretadas". Así, las estructuras narrativas imponen a las audiencias lidiar con textualidades muy complejas.

La convergencia tecnológica está propiciando la combinación de uno o varios medios de comunicación en procesos transmediales caracterizados por la capacidad narrativa de crear o expandir múltiples plataformas (Orozco, 2011). Las narrativas transmedia que se despliegan a lo largo y ancho del universo mediático desarrollan en las audiencias habilidades de significación que enriquecen sus procesos cognitivos y de producción de contenidos.

Carlos Scolari (2013, p. 46) define las narrativas transmedia como: "un tipo de relato donde la historia se despliega a través de múltiples medios y plataformas de comunicación y en el cual una parte de los consumidores asume un rol activo en ese proceso de expansión”. ¿Qué motivación tienen los prosumidores para participar del proceso de expansión narrativa? ¿Cómo influyen las narrativas transmedia en los procesos de aprendizaje y generación de conocimiento a partir de la participación activa de los comunicantes?

El hacer narrativo, entendido como una práctica de interpretación y producción de sentido transmediático, debería tener un lugar más significativo en los procesos de enseñanza-aprendizaje (Scolari, 2011). Existen muchas voces que cuestionan la importancia de las interacciones comunicativas debido a la brecha digital (que aún sigue siendo bastante amplia en la mayoría de los países latinoamericanos), pero ante este argumento cabría preguntar si cuando en los albores del siglo pasado la tecnología-libro ganaba cada vez más importancia, se debió detener la investigación y la promoción del libro en espera de que el total de la población alcanzara el acceso a la lectura y escritura. Que una tecnología no esté al alcance de toda la sociedad no implica que sea menos relevante, al reflexionar acerca de su influencia en las prácticas educativas y de enseñanza-aprendizaje. 
Las posibilidades que brinda Internet dentro de la convergencia, potencializan la acción de las audiencias, permitiendo expandir sus gustos ficcionales en múltiples plataformas y lenguajes. Al respecto, es preciso abordar la relación entre las narrativas transmedia como posibilidad para ampliar la cultura de la participación y los procesos que ocurren en los usuarios y los conduce a contribuir en la expansión de los universos narrativos.

Discutir en cuanto al comportamiento entre estudiantes e instituciones, se antoja complejo sin mediar la importancia de las tecnologías y dispositivos informacionales. Hablar de aburrimiento es apenas una provocación para destacar que existe un ecosistema hipermedial que exige nuevas categorías y maneras de ver y afrontar los problemas. Suponer que solo se necesita incorporar las tecnologías informacionales a las aulas educativas, es caer en el extremo del reduccionismo para comprender las dinámicas de significación y apropiación.

El tema del aburrimiento se ha presentado entonces como un modo sugerente de pensar el distanciamiento institucional entre profesores y alumnos, a la luz de las mutaciones que ocurren en los aprendizajes (como la prevalencia de la cultura visual y participativa por encima de la lectura y la escritura como formas de creación de contenidos). Bajo esta categoría no se trata de convertirse en el bufón de los alumnos, sino de reconocer y contrastar una experiencia frente a otra. La del alumno con su capacidad de leer imágenes y ausencia de cultura letrada, con la posición simétrica del lado del docente.

No se trata de reducir los problemas y fenómenos cotidianos a una simplificación del tipo: "los chicos se aburren y no prestan atención, entonces habrá que incorporar dispositivos en los que no se aburran", sino de entender que existen otras maneras en que es posible generar experiencias significativas para los estudiantes y naturalizar el uso de herramientas (mirando principalmente las experiencias y actividades que ya de por sí los estudiantes desarrollan cotidianamente) y tecnologías en las aulas, más allá de una incorporación simplona.

Es prioridad para las instituciones educativas, reconocer que están ocurriendo mutaciones en las formas de aprender y generar significados a la luz de la participación y uso de los nuevos medios y las tecnologías de la información y la comunicación, las cuales no pueden dejarse de lado. En este sentido, como sugiere Baricco (2009, p. 34), “Los bárbaros están aquí. La mutación ya llegó y como una pesadilla radioactiva se ha 
infiltrado en nuestras ciudades. No sirve de nada acumular botellas de agua mineral o libros impresos: nada volverá a ser como antes", o se aprende a convivir y trabajar junto a los bárbaros, regenerando los espacios de producción, transmisión y distribución del conocimiento, o terminarán todos (docentes y alumnos) engrosando las listas de los aburridos. Cada día se perfilan nuevas propuestas, experiencias y proyectos que apuntan hacia otra dirección: la creación colectiva de conocimientos, los polialfabetismos y la implementación de procesos educativos más transparentes y abiertos.

En este tono, se concluye con una idea poderosa de Paulo Freire: "El estudio no se mide por el número de páginas leídas en una noche, ni por la cantidad de libros leídos en un semestre. Estudiar no es un acto de consumir ideas, sino de crearlas y recrearlas." En esos procesos es donde se deben concentrar los esfuerzos.

\section{Referencias}

Aparici, Roberto. (2005). Medios de comunicación y educación. Revista de Educación, (338), 85-99.

Aparici, Roberto. (2011). Principios pedagógicos y comunicacionales de la educación 2.0. Revista Digital La educación, (145). Recuperado de http://www.educoas.org/portal/La Educacion Digital/laeducacion 145/articles/Robert o Aparici.pdf

Aparici, Roberto y Silva, Marco. (2012). Pedagogía de la interactividad. Comunicar. Revista Científica de Comunicación y Educación, 29(38), 51-58.

Baricco, Alessandro. (2009). Los bárbaros. Ensayo sobre la mutación. Barcelona, España: Anagrama.

Basalla, George. (1991). La evolución de la tecnologia. México: Grijalbo.

Bauman, Zygmunt. (2005). Los retos de la educación en la modernidad líquida. Barcelona, España: Gedisa.

Carr, Nicholas. (2011). Superficiales ¿Qué está haciendo Internet con nuestras mentes?. México: Taurus.

Castells, Manuel. (2009). Comunicación y poder. España: Alianza Editorial.

Cano, Elena. (2012). Aprobar o aprender. Estrategias de evaluación en la sociedad red. Barcelona, España: Col.lección Transmedia XXI. Laboratori de Mitjans Interactius. Universidad de Barcelona. 
Cobo, Cristobal y Moravec, John. (2011). Aprendizaje invisible. Hacia una nueva ecologia de la educación. Barcelona, España: Col.lección Transmedia XXI. Laboratorio de Mitjans Interactius. Universidad de Barcelona.

Crovi, Delia. (2002). Sociedad de la información y el conocimiento. Entre el optimismo y la desesperanza. Revista Mexicana de Ciencias Políticas y Sociales, 45(185), 13-33.

Corea, Cristina. (2004). Pedagogía del aburrido. Escuelas destituidas, familias perplejas. Argentina: Paidós.

Dussel, Inés. (2009). La escuela y los nuevos medios digitales. Notas para pensar las relaciones con el saber en la era digital. En Alejandro Sarbach, Filosofar con jóvenes (pp. 9-34). Córdoba, Argentina: Salida al mar Ediciones-Eduvim.

Dussel, Inés. (2013). Optimista prudencia ante las nuevas tecnologías. Revista Mexicana Investigación Educativa, 18(56), 309-315.

Feixa, Carles. (2010). Escuela y cultura juvenil: ¿matrimonio mal avenido o pareja de hecho? Revista Educación y Ciudad, (18), 7-17.

Ferrés, Joan. (2000). Educar en una cultura del espectáculo. Barcelona: Paidós.

Ferrés, Joan. (2008). La educación como industria del deseo, un nuevo estilo comunicativo. Barcelona, España: Gedisa.

Ferrés, Joan. (2011). Cambio de paradigma en la educación mediática. Cuatro razones y una conclusión. Educación mediática y competencia digital. Recuperado de http://www.educacionmediatica.es/comunicaciones/Eje\%201/Joan\%20Ferr\%C3\%A9s .pdf .

Islas, Octavio. (2011). El mundo después de McLuhan. Revista Latinoaméricana de Ciencias de la Comunicación, (14), 62-69.

Jiménez, Camilo. (2011). ¿Por qué dejo mi cátedra en la universidad? [Blog internet]. Recuperado de http://elojoenlapaja.blogspot.mx/2011/12/por-que-dejo-mi-catedra-enla.html

Johnson, Larry, Adams, Samantha, Cummins, Malcom, Estrada, Victoria, Freeman, Alex y Ludgate, Holly. (2013). The NMC Horizon Report: 2013 Higher Education Edition. Texas: NMC Horizon Report.

Liñares, Cecilia, Rivero, Yisel, Velleggia, Susana, y Zermeño, Ana. (2009). Educomunicación en México, Cuba y Argentina: un recuento de experiencias. Habana: Fundación del Nuevo Cine Latinoamericano.

Lull, James. (2008). Los placeres activos de expresar y comunicar. Comunicar. Revista Científica de Comunicación y Educación, 15(30), 21-26. 
Martín-Barbero, Jesús. (1997). Heredando el futuro. Pensar la educación desde la comunicación. Nómadas (Col), (5), 10-30.

Scolari, Carlos. (2008). Hipermediaciones. elementos para una teoría de la comunicación digital interactiva. Barcelona: Gedisa.

Scolari, Carlos. (2009). Desfasados. Las formas de conocimiento que estamos perdiendo, recuperando y ganando. Versión, (22), 163-185.

Scolari, Carlos. (2011). Convergencia, medios y educación. Nuevos desafios para la educación en Latinoamérica. Red Latinoaméricana de portales educativos. Recuperado de http://www.relpe.org

Scolari, Carlos. (2013). Narrativas Transmedia. Cuando todos los medios cuentan). España: Desuto-Grupo Planeta.

Orozco, Guillermo. (2004). De la enseñanza al aprendizaje: desordenamientos educativocomunicativos en los tiempos, escenarios y procesos de conocimiento. Nómadas, No. 21, Revista Universidad Central (p120-127).

Orozco, Guillermo. (2011). La condición comunicacional contemporánea. Desafíos latinoamericanos de la investigación de las interacciones en la sociedad red. En Nidia Jacks (ed.), Análisis de recepción en América Latina: Un recuento histórico con perspectivas al futuro (pp. 377-408). Quito: CIESPAL.

Orozco, Guillermo. (2012). "Cuatro décadas de analizar la recepción de medios en México", en Vega Montiel, A. (Coord.) La comunicación en México. Una agenda de investigación, México, DF.

Pedró, Francesc. (2011). Tecnología y escuela: lo que funciona y por qué. Fundación Santillana. 